Hydrol. Earth Syst. Sci. Discuss., 6, 121-150, 2009 www.hydrol-earth-syst-sci-discuss.net/6/121/2009/ (C) Author(s) 2009. This work is distributed under the Creative Commons Attribution 3.0 License.

\title{
Daily reservoir inflow forecasting combining QPF into ANNs model
}

\author{
Jun Zhang, Chun-tian Cheng, Sheng-li Liao, Xin-yu Wu, and Jian-jian Shen \\ Dept. of Civil \& Hydraulic Engineering, Dalian Univ. of Technology, Dalian 116024, China \\ Received: 28 August 2008 - Accepted: 5 November 2008 - Published: 6 January 2009 \\ Correspondence to: Chun-tian Cheng (ctcheng@dlut.edu.cn) \\ Published by Copernicus Publications on behalf of the European Geosciences Union.
}

121

\begin{abstract}
Daily reservoir inflow predictions with lead-times of several days are essential to the operational planning and scheduling of hydroelectric power system. The demand for quantitative precipitation forecasting (QPF) is increasing in hydropower operation with 5 the dramatic advances in the numerical weather prediction (NWP) models. This paper presents a simple and an effective algorithm for daily reservoir inflow predictions which solicits the observed precipitation, forecasted precipitation from QPF as predictors and discharges in following 1 to 6 days as predicted targets for multilayer perceptron artificial neural networks (MLP-ANNs) modeling. An improved error back-propagation

10 algorithm with self-adaptive learning rate and self-adaptive momentum coefficient is used to make the supervised training procedure more efficient in both time saving and search optimization. Several commonly used error measures are employed to evaluate the performance of the proposed model and the results, compared with that of ARIMA model, show that the proposed model is capable of obtaining satisfactory forecast-

15 ing not only in goodness of fit but also in generalization. Furthermore, the presented algorithm is integrated into a practical software system which has been severed for daily inflow predictions with lead-times varying from 1 to 6 days of more than twenty reservoirs operated by the Fujian Province Grid Company, China.
\end{abstract}

\section{Introduction}

Daily reservoir inflow forecasting with lead-times of several days has important significance to the operational planning and scheduling of hydroelectric power system, such as minimizing the thermal power generation or peak-energy maximization. However, due to the complexity of hydrological system characterized by dynamic, uncertain, and nonlinear, forecasting of daily reservoir inflow is still one of the most difficult issues in hydrological science up to now. During the past few decades, a great deal of research has been devoted to the formulation and development of approaches and models to 
improve the quality of hydrological prediction, including mechanistic models (Jacquin and Shamseldin, 2006; Mwakalila et al., 2001; Refsgaard, 1997; Romanowicz, 2007; Yu-Chi et al., 2006) and black-box models (Jain and Srinivasulu, 2004; Lin et al., 2006; Liong and Sivapragasam, 2002; Nayak, 2008; Yu et al., 2006). The mechanistic mod-

5 els, which have been studied for more than fifty years and widely used nowadays, lay emphasis on the description of physical laws and try to make a comprehensive and incisive understanding of every step in rainfall-runoff (RR) processes. However, the mechanistic models used to model such processes would require a large amount of high-quality data associated with hydrological, meteorological, natural geographical 10 characteristics as well as human activities, while the burden of data constrains the application of mechanistic models. For a large scale of hydropower system, selecting one of mechanistic models will be difficult because of lack of data. In contrast, the black-box models, that at first were only designed to identify the connection between inputs and outputs, are widely applied to forecast the streamflow because of their requirement of

15 little data and their simple formulation. The earlier methods include time series techniques and multiple linear regression methods (Irvine and Eberhardt, 1992; James, 1991). As an alternative to the aforementioned mathematical models, ANNs, which map the input to output without the need to identify the physics a priori, have been widely applied to hydrology field (ASCE Task Committee, 2000; Atiya et al., 1999;

20 Dawson and Wilby, 2001; Luk et al., 2000; Maier and Dandy, 2000). Some applications of ANNs in hydrological predictions can be found in literatures (Aqil et al., 2007; Birikundavyi et al., 2002; Campolo et al., 2003; Chau, 2006, 2007; Coulibaly et al., 2000; Dawson et al., 2006; Dibike and Solomatine, 2001; El-Din and Smith, 2002; Firat, 2008; Hu et al., 2005; Jain and Kumar, 2007; Karunasinghe and Liong, 2006; Kisi, 25 2004, 2007, 2008; Liong et al., 2000; Rajurkar et al., 2004; Shamseldin et al., 2002; Shamseldin et al., 2007; Wang et al., 2006; Wu and Chau, 2006).

With the rapid progresses of the Numerical Weather Prediction (NWP), quantitative precipitation forecasting (QPF) has been developed to an operationally feasible extent for hydrological forecasting (Collier and Kzyzysztofowicz, 2000; Krzysztofow-

123

icz and Collier, 2004) and gradually applied in some regions of the world reported by literatures in recent years. A European-scale flood forecasting system (EFFS) had been developed to make a probabilistic assessment of $n$-day ahead discharge exceedence risk $(n<10)$ with the help of the QPF from the European Centre for Medium

5 Range Weather Forecasting (ECMWF) Ensemble Prediction System (De Roo et al., 2003). Brath et al. (2002) employed short-term rainfall forecasting as input of several non-parametric hydrological models to update the discharges forecasting and the results showed a remarkable improvement could be achieved compared with the discharges from conceptual model alone. Habets et al. (2004) used QPF from two nu10 merical weather prediction models, namely ARPEGE and ALADIN, to forecast daily streamflow in Rhone basin, France, and concluded that the utility of precipitation prediction could improve the accuracy of long-duration floods forecasting. Collischonn et al. (2005) made use of QPF given by a regional numerical weather prediction model through a distributed hydrological model to perform a continuous 167-days discharge

15 forecasting of River Uruguay basin, Brazil, and suggested that the usefulness of rainfall forecasting should be improved. His another work (Collischonn et al., 2007) demonstrated that the forecast errors could be reduced considerably comparing with ARMA model. Reggiani and Weerts (2008) outlined a methodology to produce probabilistic quantitative precipitation forecasting for river flow prediction.

20 China is one of the biggest developing countries in the world and hydropower power plays an increasingly important role in its modernization process. Because of energy shortage, environmental pollution, ecological destruction, etc., hydropower is strongly advocated by the recent National Five Year Plans and more reservoirs and hydropower plants will be built for power generation in next 10 years. Therefore, accu-

25 rate daily reservoir inflow forecasting is urgently required for the operational planning and scheduling of hydroelectric power system. The new generation national MediumRange Numerical Weather Prediction (NWP) system, named T213L31, was built in 2002 and the QPF information of the most regions in the country could be obtained from this system but there were few reports about its application in hydrological fore- 
casting. So, this study will make use of QPF information for daily reservoir inflow forecasting using a simple model - BP neural network. In order to make the training process more efficient, the standard back-propagation algorithm is improved by using self-adaptive learning rate and self-adaptive momentum coefficient which can

5 import the error function variation into the adjustment of weights matrix and biases matrix. A statistic method which makes use of auto-correlation function (ACF) and crosscorrelation function (CCF) functions is employed to specify the most efficient predictors' lags which were generally selected by empiricism. The proposed model is applied to daily reservoir inflow forecasting and the results are compared with a traditional linear

10 model - Autoregressive Integrated Moving Average (ARIMA) model as the bench-mark model. Furthermore, the presented study is integrated into a practical software system which has been severed for daily inflow predictions with lead-times varying from 1 to 6 days of more than twenty reservoirs operated by the Fujian Province Grid Company, China. The context of this paper is organized as follows: The description of the

15 study area and data collection is introduced in Sect. 2. Then, Sect. 3 discusses the methodology and modelling procedure of R-R simulation and the results are discussed in Sect. 4. The web-based daily reservoir inflow forecasting system (WDRIFS) which integrated the method, modeling and algorithm in this study is described in Sect. 5 and the conclusions are given in Sect. 6 .

\section{Study area and data collection}

The study area is located in Fujian province, which owns the most important regional power grids of China and hydropower makes approximate $50 \%$ contribution of the whole electric power generation capacity. This area, as shown in Fig. 1, is bounded by the Taiwan Strait and Zhejiang, Jiangxi, and Guangdong provinces, southeastern

25 China between $23^{\circ} 31^{\prime}-28^{\circ} 19^{\prime} \mathrm{N}$ and $115^{\circ} 50^{\prime}-120^{\circ} 44^{\prime} \mathrm{E}$, and is comprised of eight hydrographic basins named Minjiang, Jiulongjiang, Jinjiang, Tingjiang, Jiaoxi, Ao'jiang, Huotongxi, and Mulanxi. Because of the typical sub-tropical oceanic monsoon climate

and mountain landforms, this area suffers from abundant but uneven temporal and spatial distributed precipitation with the mean annual rainfall between $1400 \mathrm{~mm}$ and $2000 \mathrm{~mm}$ and more than $70 \%$ of that occurs in summer from April to September. The runoff in this area has similar characteristics as the precipitation makes the major con-

5 tribution to its generation. The mean annual runoff volume of Minjiang which is the largest river in this area and has a drainage area of $61000 \mathrm{~km}^{2}$, is approximate 63 billion cubic meters. This numeral occupies 7 th place in China and exceeds about $10 \%$ that of the Yellow River whose drainage area is 12 times bigger than that of Minjiang.

There are about sixty reservoirs in this area and more than twenty of them, which

10 locate in main stream and have regulating storage, are selected in this study due to their great significance to the downriver industry and population. Although discharge and rainfall have been recorded since 1990 for most of the reservoirs, some of the data in initial years were not verified or lost, in addition, the condition of some basins had been changed by the implementation of new hydrological projects during 1990-2000, so, daily average discharges and rainfalls from 1 January 2000 to 31 December 2007 are used to calibrate and validate the model. The QPF information is collected from nine regions forecasted for the same day and next two days by the new generational medium-range NWP system in national meteorological observatory of China at 08:00 a.m. every day.

20 Shuikou, which is the most important reservoir in the study area, will be taken as an example and illustrated in detail for the modelling procedure and result analysis.

\section{Methodology and modeling}

\subsection{Predictors and forecasting targets}

There are three variables which have relation to the reservoir daily inflow as follows: the antecedent observation of rainfall and discharge, the QPF for following days and the seasonal information. 
For every day $t$, four MLP-ANNs models, namely Model $(t+i) i=0,1,2,3$, are developed for the daily reservoir inflow forecasting with lead-times (represented by symbol i) varying from 1 to 6 days. The Model $(t+i) i=0,1,2$ makes use of the different QPF for the first three days whereas the $\operatorname{Model}(t+3)$ is a unified model for the next four days

5 since no QPF more than three days is available at present.

A statistic perspective, proposed by Sudheer (2002), is used here to select the antecedent predictors which have the most significant effect on the inflow of following days. By means of this approach, the lag number of antecedent discharge is determined by auto-correlation function (ACF) and the lag number of antecedent rainfall is

10 decided by cross-correlation function (CCF). For Shuikou reservoir, the results of ACF and CCF statistic analysis, as shown in Fig. 2, indicate that antecedent one-day discharge ( $\max A C F=0.857$ ) and antecedent two-day rainfalls (max $C C F=0.678$ ) should be chosen into the predictors.

So, the models can be demonstrated by four equations as follows:

$15 \operatorname{Model}(t+0)$ :

$Q(t+1)=f(P(t-2), P(t-1), Q(t-1), Q P F(t), \bar{P}(30), \bar{Q}(30))$

Model $(t+1)$ :

$Q(t+1)=f(P(t-2), P(t-1), Q(t-1), Q P F(t), Q P F(t+1), \bar{P}(30), \bar{Q}(30))$

Model $(t+2)$ :

20

$Q(t+2)=f(P(t-2), P(t-1), Q(t-1), Q P F(t), Q P F(t+1), Q P F(t+2), \bar{P}(30), \bar{Q}(30))$

Model $(t+3)$ :

$Q(t+i)=\operatorname{Model}(t+0) \quad i=3,4,5,6 ; \operatorname{QPF}(t)=0$

in which $Q P F$ is the quantitative precipitation forecasting, $P$ and $Q$ are the antecedent observed rainfall and discharge, $\bar{P}(n)$ and $\bar{Q}(n)$ are the mean values of the observed rainfall and discharge of antecedent $n$ days as the seasonal information.

\subsection{Architecture of MLP-ANNs models}

The MLP-ANNs used in this study is a feed forward neural network which generally consists of three layers viz. input, hidden, and output layer. There are a mass of interconnected and parallel processed neurons (namely node) in every layer, and each 5 neuron can transfer an input of vector variable to an output of scalar variable through a nonlinear function called "Sigmoid". The input layer is connected with the predictors outside, synchronously the output layer connects to the predictands, and the hidden layer is the connective bridge of them. The signal from "normalized" predictors, according to "feed forward" mode, is transmitted in order from the input layer through the

10 hidden layer to the output layer, and is finally converted to the predictands.

The determination of the number of neurons in each layer is also an essential task. For the input layer and the output layer, the neurons number can be easily specified according to the number of predictors and predictands, respectively. However, the determination of neuron number in hidden layer, which is crucial for the success of

15 the networks, is still a difficult procedure until now. So, an experiment with a trialand-error measure, recommended as the best strategy by Shamseldin (1997), is used in our work. The experimental results indicate that the numbers of neurons in the hidden layer, for Shuikou reservoir, are 12, 15 and 20 for $\operatorname{Model}(t+0)$, Model $(t+1)$ and Model $(t+2)$, respectively.

\subsection{Improved error back-propagation algorithm}

The error back-propagation algorithm is widely used to adjust the weights matrix and the biases matrix of the networks through an iterative training procedure for the purpose of revealing the relationship between the predictors and the predictands. From an initial random weights matrix and bias matrix, this algorithm searches the "weight space" by

25 using gradient descent method to minimize the overall error between the simulated outputs and the observed values.

A method with self-adaptive learning rate and self-adaptive momentum coefficient is 
used here to accelerate the training process and to prevent the algorithm from converging at a local minimum. The learning rate $\alpha$ and the momentum coefficient $\beta$ are automatically adjusted as follows (Sun et al., 2007):

(a) when $e_{r}^{(k)}<0$

$5\left\{\begin{array}{l}\alpha(k+1)=\alpha(k)\left[1+u \cdot e^{-e_{r}(k)}\right] \\ \beta(k+1)=\beta(k)\left[1+v \cdot e^{-e_{r}(k)}\right]\end{array}\right.$

(b) when $e_{r}^{(k)} \geq 0$

$$
\left\{\begin{array}{l}
\alpha(k+1)=\alpha(k)\left[1-u \cdot e^{-e_{r}(k)}\right] \\
\beta(k+1)=\beta(k)\left[1-v \cdot e^{-e_{r}(k)}\right]
\end{array}\right.
$$

where $k$ is the epoch index, $u, v \in(0,1)$ are two parameters $(0.5$ and 0.5 in this study), and $e_{r}^{(k)}$ is an artificial coefficient, indicates the direction of the overall error which is defined as follows:

$e_{r}^{(k)}=\frac{\Delta E(k)}{E(k)}=\frac{E(k)-E(k-1)}{E(k)}$

By this dynamical adjustment, the learning rate increases when the overall error reduces and decreases when the overall error increases over a certain rate. Additional momentum term is used to import the effect caused by the changes of the weights 15 matrix in the previous epoch and this item can effectively smooth the descending path and prohibit converging at a local minimum. So, the change of weights matrix $w_{j i}$ and bias matrix $q_{j}$ are adjusted as follows:

$$
\left\{\begin{array}{c}
\Delta w_{j i}(k+1)=\sum_{p=1}^{P} \alpha_{j} d_{p j} x_{i}+\beta_{j} \Delta w_{j i}(k) \\
\Delta q_{j}(k+1)=\sum_{p=1}^{P} \alpha_{j} d_{p j}+\beta_{j} \Delta q_{j}(k)
\end{array}\right.
$$

in which $p=1,2, \ldots P$ presents the $p$ th training pattern.

\subsection{Performance assessment measures}

A number of error measures (Dawson et al., 2007; Legates and McCabe, 1999) have been developed to assess the goodness of fit performance of hydrological forecasting models but no standard has been specified since each measure can just assess one or

5 two aspects of the runoff characteristics. Five commonly used error measures, therefore, are employed in this study to make the evaluation of the forecasting. They are the coefficient of efficiency (CE), the mean absolute error (MAE), the mean squared relative error (MSRE), the relative volume error (RVE) and the coefficient of determination $\left(R^{2}\right)$, respectively defined as follows:

$$
\begin{aligned}
\text { 10 } & =1-\frac{\sum_{i=1}^{n}\left(Q_{i}-\widehat{Q}_{i}\right)^{2}}{\sum_{i=1}^{n}\left(Q_{i}-\bar{Q}\right)^{2}} \\
\text { MAE } & =\frac{\sum_{i=1}^{n}\left|Q_{i}-\widehat{Q}_{i}\right|}{n} \\
\text { MSRE } & =\frac{\sum_{i=1}^{n} \frac{\left(Q_{i}-\hat{Q}_{i}\right)^{2}}{Q_{i}^{2}}}{n} \\
\operatorname{RVE} & =\frac{\sum_{i=1}^{n}\left(Q_{i}-\widehat{Q}_{i}\right)}{\sum_{i=1}^{n}\left(Q_{i}\right)} \\
R^{2} & =\left[\frac{\sum_{i=1}^{n}\left(Q_{i}-\bar{Q}\right)\left(\widehat{Q}_{i}-\widetilde{Q}\right)}{\sqrt{\sum_{i=1}^{n}\left(Q_{i}-\bar{Q}\right)^{2}\left(\hat{Q}_{i}-\widetilde{Q}\right)^{2}}}\right]^{2}
\end{aligned}
$$

15 where $Q_{i}$ is the observed discharge, $\widehat{Q}_{i}$ is the simulated discharge, $\bar{Q}$ is the mean of the observed discharges, $\widetilde{Q}$ is the mean of the simulated discharges and $n$ is the length of the observed/simulated series.

The CE (Nash and Sutcliffe, 1970), which ranges from $-\infty$ to 1 , describes the rela- 
tionship between the modeled value and the mean of the observed data. A coefficient of one $(C E=1)$ means that the model performs a perfect matching to the observed data, a coefficient of $(C E=0)$ indicates that the modeled result just has the equal mean value with the observed data, whereas a coefficient of negative value $(C E<0)$ shows that the

5 model performs worse than using the observed mean.

The MAE, which ranges from 0 to $+\infty$, is used to measure how close forecasts are to the eventual outcomes. Theoretically, a coefficient of zero $(M A E=0)$ means the best model with a perfect performance.

The MSRE, which ranges from 0 to $+\infty$, can provide a balanced evaluation of the 10 goodness of fit of the model as it is more sensitive to the larger relative errors caused by the low valued and the best coefficient will be zero (MSRE=0).

The RVE, gives the relative bias of the overall water balance of the model and the best coefficient will be zero (RVE=0).

The $R^{2}$, which ranges from 0 to 1 , is a statistical measure of how well the regres-

15 sion line close to the observed data and a coefficient of one $\left(R^{2}=1\right)$ indicates that the regression line perfectly fits the observed data.

\section{Results and discussions}

The goodness of fit performances of calibration from 1 January 2000 to 31 December 2005 and validation from 1 January 2006 to 31 December 2007 are illustrated in

20 Figs. 3 and 4, respectively, and the statistic result of error measures is given in Table 1. Figure 5 shows the relevant scatter diagrams of simulated discharge versus observed discharge of Model $(t+0)$, Model $(t+1), \operatorname{Model}(t+2)$ and ARIMA in calibration (Fig. 5a-d) and validation (Fig. $5 \mathrm{e}-\mathrm{h}$ ).

Figures 3 and 4 present the daily rainfall sequence and discharge sequence continually and the simulated results from three different models are synchronously given with the observed records in each figure. The simulated curves in both Figs. 3 and 4 clearly indicate that not only the rising trends and the falling trends in the hydrograph

are picked up by Model $(t+0)$, Model $(t+1)$ and Model $(t+2)$ but also excellent goodness of fit performances are achieved.

As shown in Table 1, the general quantitative scope of the fiver error measures indicates that the before-mentioned models are suitable for the RR process simulation.

5 Satisfactory forecasting is obtained in this study since the CE and $R^{2}$ are sufficiently high close to 1 , and the MSRE and RVE are adequately low approximates 0 . The measures MAE of calibration and validation are far less than the relevant mean value of the observed data, $1494.46 \mathrm{~m}^{3} / \mathrm{s}$ and $1643.25 \mathrm{~m}^{3} / \mathrm{s}$, respectively. The high scores of $C E$ and $R^{2}$ indicates that all the models present the "Best" performance according to the o standard given by Dawson et al. (2007).

From the scatter diagrams in Fig. 5, it is obviously that both of the low values and the high values are close to the exact fit line and this result suggests that there is no evident overestimate or underestimate occurs during the simulation.

The statistic result of error measures of the validation are as much as that of the 15 calibration and both of them are encouraging. This outcome implies that the training procedures are successful without "overtraining" or "local minimum" and the proposed models have powerful generalization abilities for out-of-sample forecasting.

The performance of the proposed model is also evaluated by comparing the forecasting results with that of a traditional linear model - $\operatorname{ARIMA}(p, d, q)$ model and the

20 basic parameters of ARIMA model $-p, d$, and $q$ are specified to be 4,1 and 2 , respectively, in this paper. As listed in Table 1, four error measures CE, MAE, MSRE and $R^{2}$ show that all the MLP-ANNs models perform much better than ARIMA model and only the RVE indicates that the ARIMA model is better. Furthermore, the scatter diagrams, as shown in Fig. 5, show that the forecasted results of our models, compared with that 25 of ARIMA model, are much more close to the exact fit line, especially for the bigger inflows. Therefore, it is clearly that the presented model outperforms ARIMA model according to our simulating experiment.

In order to investigate the affection of QPF on forecasting, we recalculated the calibration data set and the validation data set and the QPF information is eliminated from 
the input vector this time. From the quantitative results of the error measures which are listed in Table 2, it is clearly that the scores of all error measures are decreased compared with that in Table 1. Further more, with the lead-times increasing, the performances deteriorate more obviously (The scores decrease less than $5 \%$ for $\operatorname{Model}(t+0)$,

$55 \%-8 \%$ for Model $(t+1)$, and $8 \%-15 \%$ for Model $(t+2))$.

\section{Software implementation}

On the basis of the previous study, an integrated web-based daily reservoir inflow forecasting system (WDRIFS), implemented within java technology framework, has been successfully developed recently and been applied in daily inflow predictions of more than twenty reservoirs operated by the Fujian Province Grid Company, China, for the purpose of making operational planning and scheduling of hydroelectric power system.

The WDRIFS is the newest version production of hydrological forecasting software after the Chinese national flood control system for reservoirs (Cheng and Chau, 2004) and the Web-based flood forecasting system (Cheng et al., 2004). Comparing with the

15 two existed system, the WDRIFS puts more focus on the daily forecasting with relative long lead-times and the QPF information is firstly applied to the RR simulation in this system in China. The WDRIFS is developed under the condition of JBuilder 2006, Weblogic $8 \mathrm{i}$ and Oracle $10 \mathrm{~g}$, conformed to the J2EE criterion and a number of java techniques, such as Applet, Servlet, Swing, JDBC, JSP and so on, are used during the

20 implementation. By the aid of this system, a web-based forecasting of daily reservoir inflow with lead-times varying from 1 to 6 days will be automatically accomplished in time every day after the QPF is released.

This system is composed of three main function modules, namely parameter calibration module, auto forecasting module and simulation forecasting module, respec-

25 tively. Parameter calibration module is used to determine the relevant parameters of the MLP-ANNs models for every reservoir. For each model, some items should be specified before training the networks as follows: the historical data sets for calibra-

133

tion and validation, the lag number of antecedent predictors, the number of neurons in hidden layer and the termination condition. While the training procedure is processing, as shown in Fig. 6, the simulated discharge is painted together with the observed discharge dynamically and the hydrograph can be zoomed in/zoomed out by dragging

5 with mouse right button pressed to inspect the local part of the discharge sequence such as the flood peak. At the same time, the numerical simulated result and the quantitative statistic result of error measures are listed in two tables, respectively. Two error measures besides the aforementioned ones, namely mean absolute percentage error (MAPE) and qualified percentage (QP) which means the percent of the simu-

10 lated discharge with a relative error less than the specified standard, are added in this system due to their popularly usage in China. The training procedure can be paused or resumed and the hydrograph can be switched over calibration and validation. The optimal parameters will be traced and recorded to the database after the training procedure is accomplished, ended by the specified max epoch, CE, qualified percentage or the combination of them. Figure 7 shows the auto forecasting interface in which the auto forecasting plans and the QPF information together with the observed data for following six days are listed in one table. Some statistic information such as the relevant error and the qualified percentage is displayed by default and it can be hidden by changing the table header setting. The graphics mode (see Fig. 8) will be displayed

20 by clicking the table header, through which the goodness of fit performance of forecasting can be evaluated by comparing the simulated hydrograph with the observed hydrograph. When the QPF information is trustless or urgent hydropower scheduling tasks need to be arranged in advance in flood season, the seasoned hydrological experts or operators can design or assume the QPF information and make a simulation 25 forecasting based on it (see Fig. 9). In this interface, the QPF chart (the smaller one) is painted besides the forecasting chart and the QPF for every day can be reassigned by directly input in the last column of the table, or by dragging with mouse left button pressed. Once the QPF is changed by any way, the simulated discharge will be recalculated immediately and the forecasting chart will update. The approbatory simulation 
forecasting result will be saved as a manual plan of that day.

\section{Conclusions}

The future precipitation is the dominant source of uncertainty in hydrological forecasting and the current scientific advances in the QPF are feasible (Krzysztofowicz and

5 Collier, 2004). So, any research on integrating QPF into hydrological models is significant and promising for improving the quality of hydrological forecasting. This paper combines the QPF into ANNs models to perform daily reservoir inflow forecasting. Different models based on MLP-ANNs, in which the improved error back-propagation algorithm with self-adaptive learning rate and self-adaptive momentum coefficient is used to make the supervised training procedure more efficient both in time saving and search optimization, are developed to simulate daily reservoir inflow with lead-times of several days. The experimental results indicate that these models can extend the forecasting lead-times with a satisfactory goodness of fit performance and the precision of the forecasting results are much better than traditional ARIMA model. As the 15 application of this study, an integrated web-based daily reservoir inflow forecasting system (WDRIFS), implemented within java technology framework, is developed and has been severed for daily inflow predictions with lead-times varying from 1 to 6 days of more than twenty reservoirs operated by the Fujian Province Grid Company, China. The primary interfaces and functions of this system are presented in detail in this pa20 per.

Acknowledgements. This study is jointly supported by the National Natural Science Foundation of China (Grant No. 50679011) and the PhD Programs Foundation of Ministry of Education of China (Grant No. 20060183043).

\section{References}

Aqil, M., Kita, I., Yano, A., and Nishiyama, S.: A comparative study of artificial neural networks and neuro-fuzzy in continuous modeling of the daily and hourly behaviour of runoff, J. Hydrol., 337, 22-34, 2007.

5 ASCE Task Committee: Artificial neural networks in hydrology. II: Hydrologic applications, J. Hydrol. Eng., 5, 124-137, 2000.

Atiya, A. F., El-Shoura, S. M., Shaheen, S. I., and El-Sherif, M. S.: A comparison between neural-network forecasting techniques - case study: river flow forecasting, IEEE T. Neural Networ., 10, 402-409, 1999.

10 Birikundavyi, S., Labib, R., Trung, H. T., and Rousselle, J.: Performance of neural networks in daily streamflow forecasting, J. Hydrol. Eng., 7, 392-398, 2002.

Brath, A., Montanari, A., and Toth, E.: Neural networks and non-parametric methods for improving real-time flood forecasting through conceptual hydrological models, Hydrol. Earth Syst. Sci., 6, 627-639, 2002,

15 http://www.hydrol-earth-syst-sci.net/6/627/2002/.

Campolo, M., Soldati, A., and Andreussi, P.: Artificial neural network approach to flood forecasting in the river Arno, Hydrolog. Sci. J., 48, 381-398, 2003.

Chau, K. W.: Particle swarm optimization training algorithm for ANNs in stage prediction of Shing Mun river, J. Hydrol., 329, 363-367, 2006.

20 Chau, K. W.: A split-step particle swarm optimization algorithm in river stage forecasting, J. Hydrol., 346, 131-135, 2007.

Cheng, C. T. and Chau, K. W.: Flood control management system for reservoirs, Environ. Modell. Softw., 19, 1141-1150, 2004.

Cheng, C. T., Chau, K. W., Li, X. Y., and Li, G.: Developing a Web-based flood forecasting system for reservoirs with J2EE, Hydrolog. Sci. J., 49, 973-986, 2004.

Collier, C. G. and Kzyzysztofowicz, R.: Quantitative precipitation forecasting, J. Hydrol., 239, $1-2,2000$.

Collischonn, W., Haas, R., Andreolli, I., and Tucci, C. E. M.: Forecasting river Uruguay flow using rainfall forecasts from a regional weather-prediction model, J. Hydrol., 305, 87-98, 2005.

Collischonn, W., Morelli Tucci, C. E., Clarke, R. T., Chou, S. C., Guilhon, L. G., Cataldi, M., and Allasia, D.: Medium-range reservoir inflow predictions based on quantitative precipitation 
forecasts, J. Hydrol., 344, 112-122, 2007.

Coulibaly, P., Anctil, F., and Bobée, B.: Daily reservoir inflow forecasting using artificial neural networks with stopped training approach, J. Hydrol., 230, 244-257, 2000.

Dawson, C. W. and Wilby, R. L.: Hydrological modelling using artificial neural networks, Prog. Phys. Geog., 25, 80-108, 2001.

Dawson, C. W., Abrahart, R. J., Shamseldin, A. Y., and Wilby, R. L.: Flood estimation at ungauged sites using artificial neural networks, J. Hydrol., 319, 391-409, 2006.

Dawson, C. W., Abrahart, R. J., and See, L. M.: HydroTest: a web-based toolbox of evaluation metrics for the standardised assessment of hydrological forecasts, Environ. Modell. Softw., 22, 1034-1052, 2007.

De Roo, A. P. J., Bartholmes, J., Bates, P. D., Beven, K., Bongioannini-Cerlini, B., Gouweleeuw, B., Heise, E., Hils, M., Hollingsworth, M., Holst, B., Horritt, M., Hunter, N., Kwadijk, J., Pappenburger, F., Reggiani, P., Rivin, G., Sattler, K., Sprokkereef, E., Thielen, J., Todini, E., and Van Dijk, M.: Development of a European flood forecasting system, Int. J. River Basin Manag., 1, 49-59, 2003.

Dibike, Y. B. and Solomatine, D. P.: River flow forecasting using artificial neural networks, Phys. Chem. Earth. Pt. B, 26, 1-7, 2001.

El-Din, A. G. and Smith, D. W.: A neural network model to predict the wastewater inflow incorporating rainfall events, Water Res., 36, 1115-1126, 2002.

20 Firat, M.: Comparison of Artificial Intelligence Techniques for river flow forecasting, Hydrol. Earth Syst. Sci., 12, 123-139, 2008, http://www.hydrol-earth-syst-sci.net/12/123/2008/.

Habets, F., LeMoigne, P., and Noilhan, J.: On the utility of operational precipitation forecasts to served as input for streamflow forecasting, J. Hydrol., 293, 270-288, 2004.

$25 \mathrm{Hu}, \mathrm{T}$. S., Lam, K. C., and Ng, S. T.: A modified neural network for improving river flow prediction, Hydrolog. Sci. J., 50, 299-318, 2005.

Irvine, K. N. and Eberhardt, A. J.: Multiplicative, Seasonal ARIMA Models for Lake Erie and Lake Ontario water levels, J. Am. Water Resour. As., 28, 385-396, 1992.

Jacquin, A. P. and Shamseldin, A. Y.: Development of rainfall-runoff models using TakagiSugeno fuzzy inference systems, J. Hydrol., 329, 154-173, 2006.

Jain, A. and Srinivasulu, S.: Development of effective and efficient rainfall-runoff models using integration of deterministic, real-coded genetic algorithms and artificial neural network techniques, Water Resour. Res., 40, W04302, 2004.

137

Jain, A. and Kumar, A. M.: Hybrid neural network models for hydrologic time series forecasting, Appl. Soft Comput., 7, 585-592, 2007.

James, A. S.: Long-range streamflow forecasting using nonparametric regression, J. Am. Water Resour. As., 27, 39-46, 1991.

5 Sudheer, K. P., Gosain, A. K., and Ramasastri, K. S.: A data-driven algorithm for constructing artificial neural network rainfall-runoff models, Hydrol. Process., 16, 1325-1330, 2002.

Karunasinghe, D. S. K. and Liong, S. Y.: Chaotic time series prediction with a global model: artificial neural network, J. Hydrol., 323, 92-105, 2006.

Kisi, O.: River flow modeling using artificial neural networks, J. Hydrol. Eng., 9, 60-63, 2004.

10 Kisi, O.: Streamflow forecasting using different artificial neural network algorithms, J. Hydrol. Eng., 12, 532-539, 2007.

Kisi, O.: River flow forecasting and estimation using different artificial neural network techniques, Hydrol. Res., 39, 27-40, 2008.

Krzysztofowicz, R. and Collier, C. G.: Quantitative precipitation forecasting II, J. Hydrol., 288, $1-1,2004$.

Legates, D. R. and McCabe, G. J.: Evaluating the use of "goodness-of-fit" measures in hydrologic and hydroclimatic model validation, Water Resour. Res., 35, 233-241, 1999.

Lin, J. Y., Cheng, C. T., and Chau, K. W.: Using support vector machines for long-term discharge prediction, Hydrolog. Sci. J., 51, 599-612, 2006.

20 Liong, S. Y., Lim, W. H., and Paudyal, G. N.: River stage forecasting in Bangladesh: neural network approach, J. Comput. Civil Eng., 14, 1-8, 2000.

Liong, S. Y. and Sivapragasam, C.: Flood stage forecasting with support vector machines, J. Am. Water Resour. As., 38, 173-186, 2002.

Luk, K. C., Ball, J. E., and Sharma, A.: A study of optimal model lag and spatial inputs to artificial neural network for rainfall forecasting, J. Hydrol., 227, 56-65, 2000.

Maier, H. R. and Dandy, G. C.: Neural networks for the prediction and forecasting of water resources variables: a review of modelling issues and applications, Environ. Modell. Softw., 15, 101-124, 2000.

Mwakalila, S., Campling, P., Feyen, J., Wyseure, G., and Beven, K.: Application of a data-based

30 mechanistic modelling (DBM) approach for predicting runoff generation in semi-arid regions, Hydrol. Process., 15, 2281-2295, 2001.

Nash, J. E. and Sutcliffe, J. V.: River flow forecasting through conceptual models part I - a discussion of principles, J. Hydrol., 10, 282-290, 1970. 
Nayak, P. C. and Sudheer, K. P.: Fuzzy model identification based on cluster estimation for reservoir inflow forecasting, Hydrol. Process., 22, 827-841, 2008.

Rajurkar, M. P., Kothyari, U. C., and Chaube, U. C.: Modeling of the daily rainfall-runoff relationship with artificial neural network, J. Hydrol., 285, 96-113, 2004.

5 Refsgaard, J. C.: Validation and intercomparison of different updating procedures for real-time forecasting, Nord. Hydrol., 28, 65-84, 1997.

Reggiani, P. and Weerts, A. H.: Probabilistic quantitative precipitation forecast for flood prediction: An application, J. Hydrometeorol., 9, 76-95, 2008.

Romanowicz, R. J.: Data based mechanistic model for low flows: implications for the effects of climate change, J. Hydrol., 336, 74-83, 2007.

Shamseldin, A. Y.: Application of a neural network technique to rainfall-runoff modelling, J. Hydrol., 199, 272-294, 1997.

Shamseldin, A. Y., Nasr, A. E., and O'Connor, K. M.: Comparison of different forms of the Multilayer Feed-Forward Neural Network method used for river flow forecasting, Hydrol. Earth

15 Syst. Sci., 6, 671-684, 2002, http://www.hydrol-earth-syst-sci.net/6/671/2002/.

Shamseldin, A. Y., O'Connor, K. M., and Nasr, A. E.: A comparative study of three neural network forecast combination methods for simulated river flows of different rainfall-runoff models, Hydrolog. Sci. J., 52, 896-916, 2007.

20 Sun, Y., Zhang, S., Miao, C. X., and Li, J. M.: Improved BP neural network for transformer fault diagnosis, J. China Univ. Min. Technol., 17, 138-142, 2007.

Wang, W., Gelder, P. H. A. J. M. V., Vrijling, J. K., and Ma, J.: Forecasting daily streamflow using hybrid ANN models, J. Hydrol., 324, 383-399, 2006.

Wu, C. L., and Chau, K. W.: A flood forecasting neural network model with genetic algorithm, Int. J. Environ. Pollut., 28, 261-273, 2006.

Yu-Chi, W., Han, D., Pao-Shan, Y., and Cluckie, I. D.: Comparative modelling of two catchments in Taiwan and England, Hydrol. Process., 20, 4335-4349, 2006.

Yu, P. S., Chen, S. T., and Chang, I. F.: Support vector regression for real-time flood stage forecasting, J. Hydrol., 328, 704-716, 2006.

Table 1. The statistic result of error measures of calibration and validation.

\begin{tabular}{|c|c|c|c|c|c|c|c|c|}
\hline \multirow{2}{*}{$\begin{array}{l}\text { Error } \\
\text { measures }\end{array}$} & \multicolumn{4}{|c|}{ Calibration } & \multicolumn{4}{|c|}{ Validation } \\
\hline & $\begin{array}{l}\text { Model } \\
(t+0)\end{array}$ & $\begin{array}{l}\text { Model } \\
(t+1)\end{array}$ & $\begin{array}{l}\text { Model } \\
(t+2)\end{array}$ & ARIMA & $\begin{array}{l}\text { Model } \\
(t+0)\end{array}$ & $\begin{array}{l}\text { Model } \\
(t+1)\end{array}$ & $\begin{array}{c}\text { Model } \\
(t+2)\end{array}$ & ARIMA \\
\hline CE & 0.9687 & 0.9682 & 0.9661 & 0.7486 & 0.9520 & 0.9263 & 0.9499 & 0.7670 \\
\hline MAE & 200.14 & 201.51 & 212.72 & 384.03 & 240.28 & 255.49 & 255.20 & 443.46 \\
\hline MSRE & 0.0554 & 0.0678 & 0.0552 & 0.1273 & 0.0450 & 0.0572 & 0.0649 & 0.1525 \\
\hline RVE & 0.0433 & 0.0306 & 0.0785 & 0.0013 & 0.0498 & 0.0536 & 0.0682 & 0.0030 \\
\hline$R^{2}$ & 0.9710 & 0.9688 & 0.9719 & 0.7476 & 0.9534 & 0.9360 & 0.9565 & 0.7675 \\
\hline
\end{tabular}


Table 2. The statistic result of error measures of calibration and validation (without $Q P F$ information).

\begin{tabular}{lcccccc}
\hline $\begin{array}{l}\text { Error } \\
\text { measures }\end{array}$ & \multicolumn{3}{c}{ Calibration } & \multicolumn{3}{c}{ Validation } \\
& $(t+0)$ & $\begin{array}{c}\text { Model } \\
(t+1)\end{array}$ & $\begin{array}{c}\text { Model } \\
(t+2)\end{array}$ & $\begin{array}{c}\text { Model } \\
(t+0)\end{array}$ & $\begin{array}{c}\text { Model } \\
(t+1)\end{array}$ & $\begin{array}{c}\text { Model } \\
(t+2)\end{array}$ \\
\hline CE & 0.9332 & 0.8924 & 0.8903 & 0.9173 & 0.8565 & 0.8067 \\
MAE & 208.35 & 216.50 & 222.62 & 251.12 & 271.14 & 276.24 \\
MSRE & 0.0561 & 0.0721 & 0.0623 & 0.0482 & 0.0610 & 0.0634 \\
RVE & 0.0450 & 0.0326 & 0.0841 & 0.0512 & 0.0564 & 0.0771 \\
$R^{2}$ & 0.9322 & 0.9156 & 0.8796 & 0.9187 & 0.8704 & 0.8424 \\
\hline
\end{tabular}

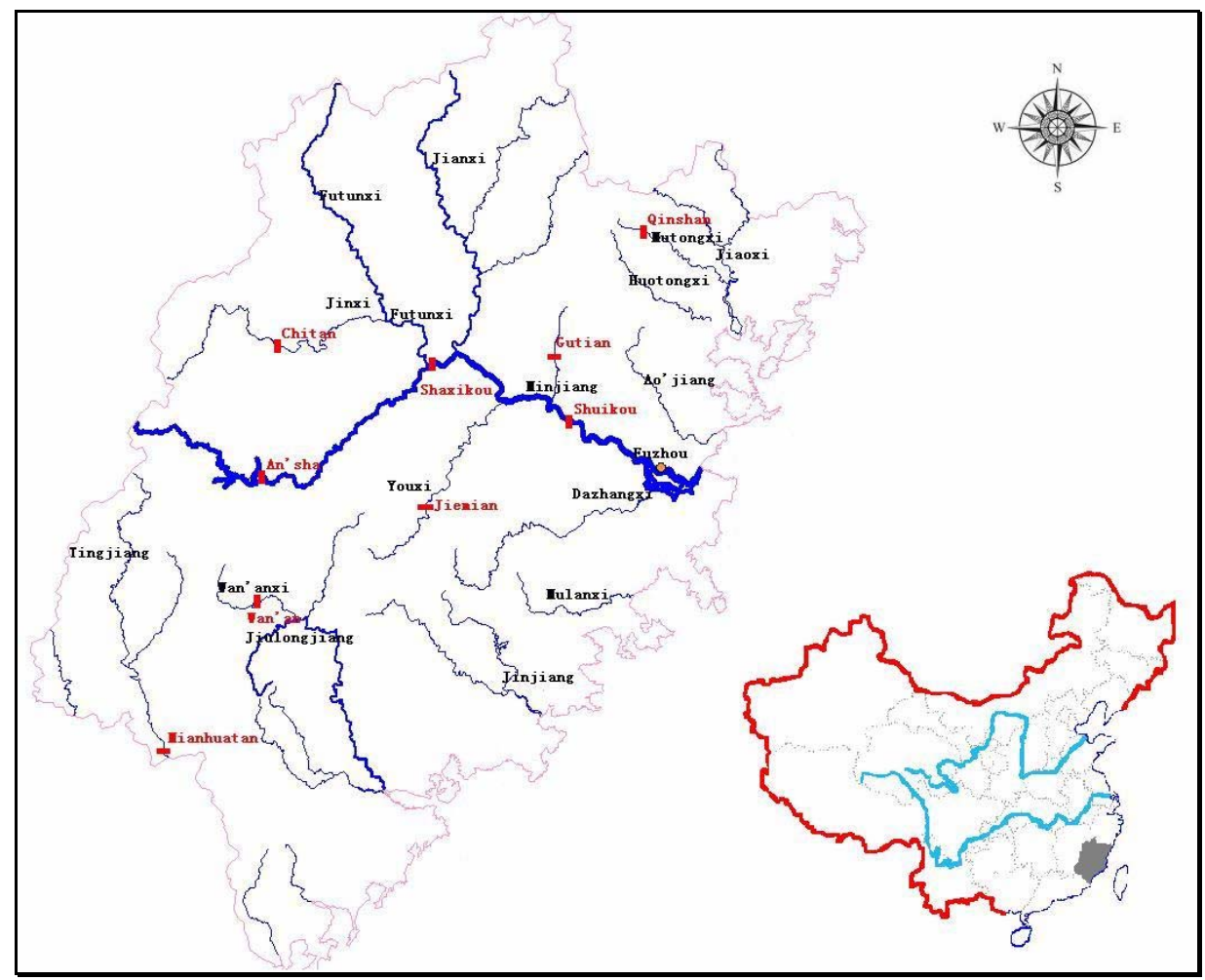

Fig. 1. The study area. 

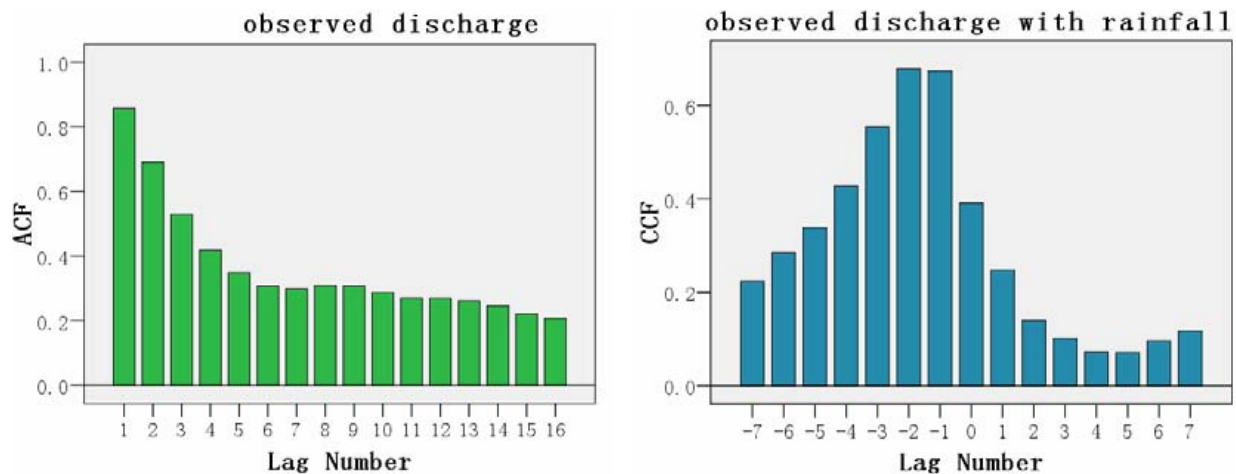

Fig. 2. The ACF and CCF statistic analysis of Shuikou reservoir.

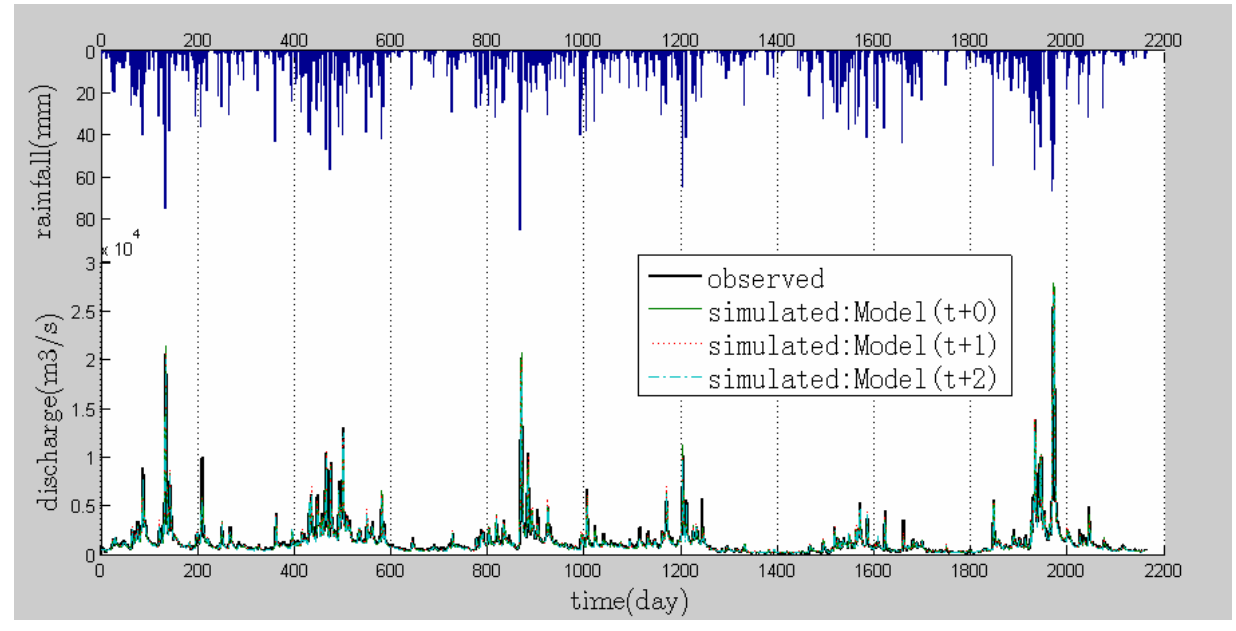

Fig. 3. Calibration result of Shuikou reservoir (2000-2005). 


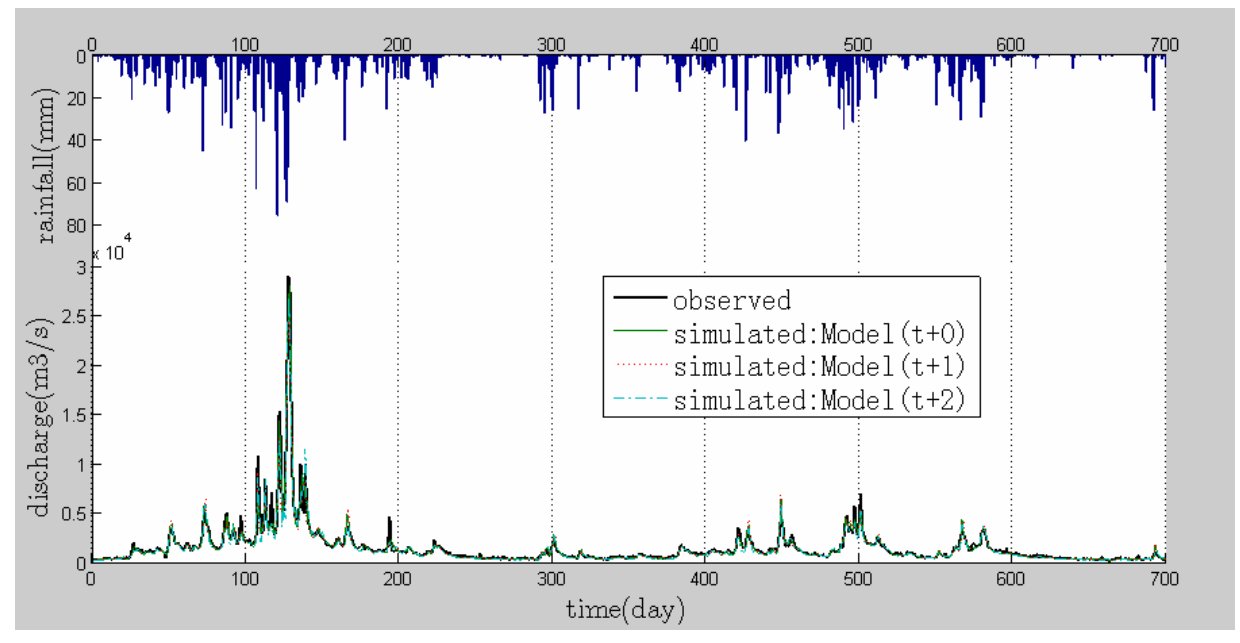

Fig. 4. Validation result of Shuikou reservoir (2006-2007).
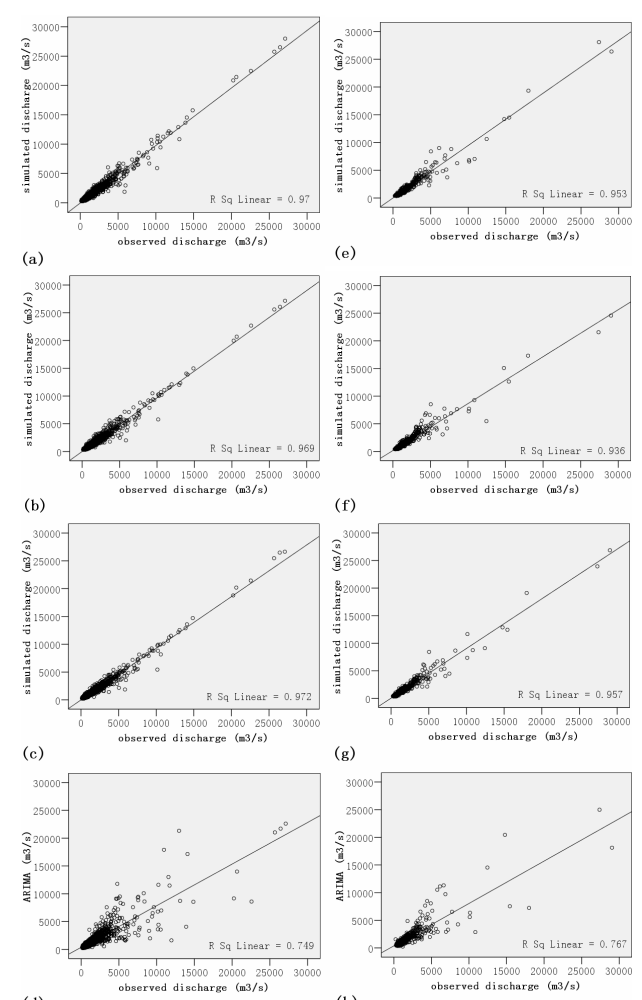

(h)

Fig. 5. Scatter diagrams of observed discharge and simulated discharge, (a) Model $(t+0)$ in calibration, (b) Model $(t+1)$ in calibration, (c) Model $(t+2)$ in calibration, (d) ARIMA in calibration, (e) Model $(t+0)$ in validation, (f) Model $(t+1)$ in validation, (g) Model $(t+2)$ in validation, (h) ARIMA in validation. 


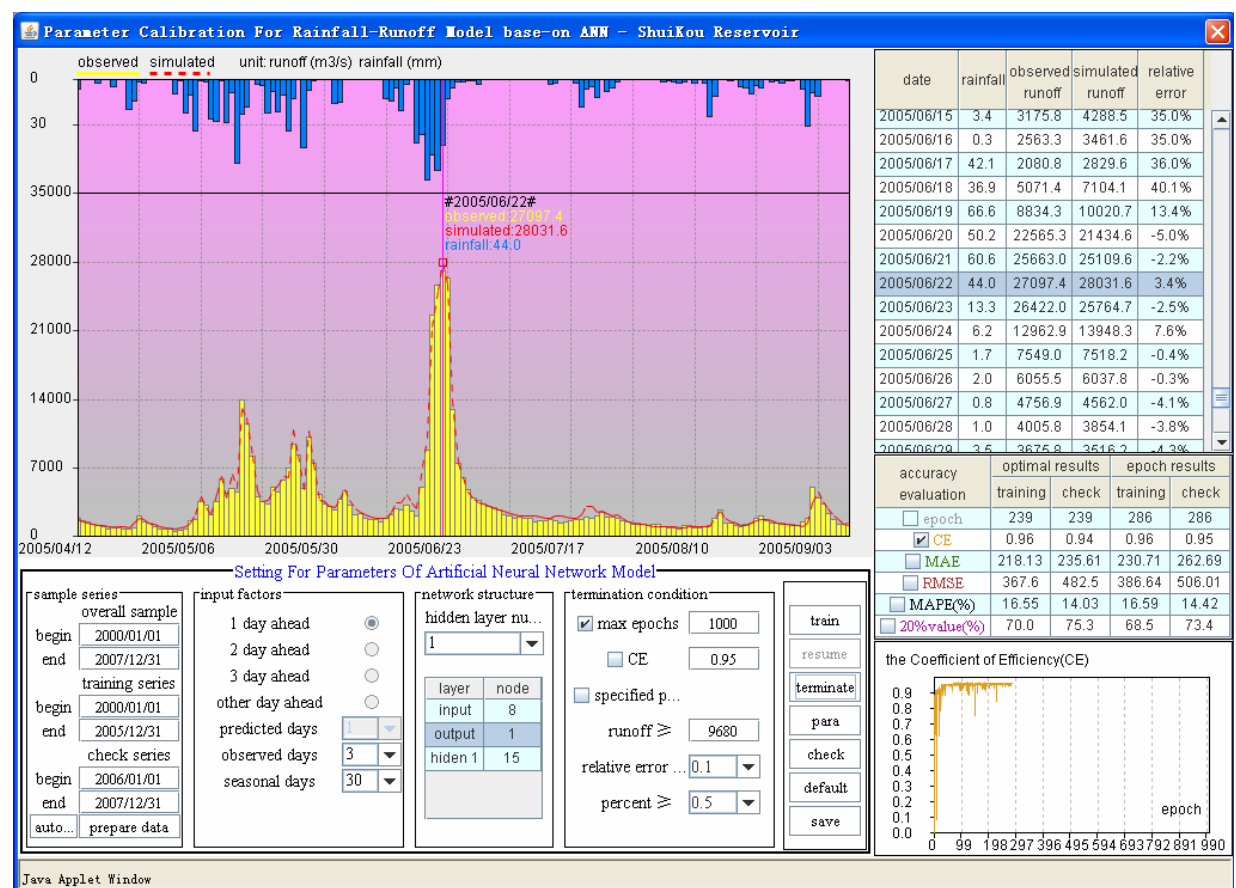

Fig. 6. The parameter calibration module.

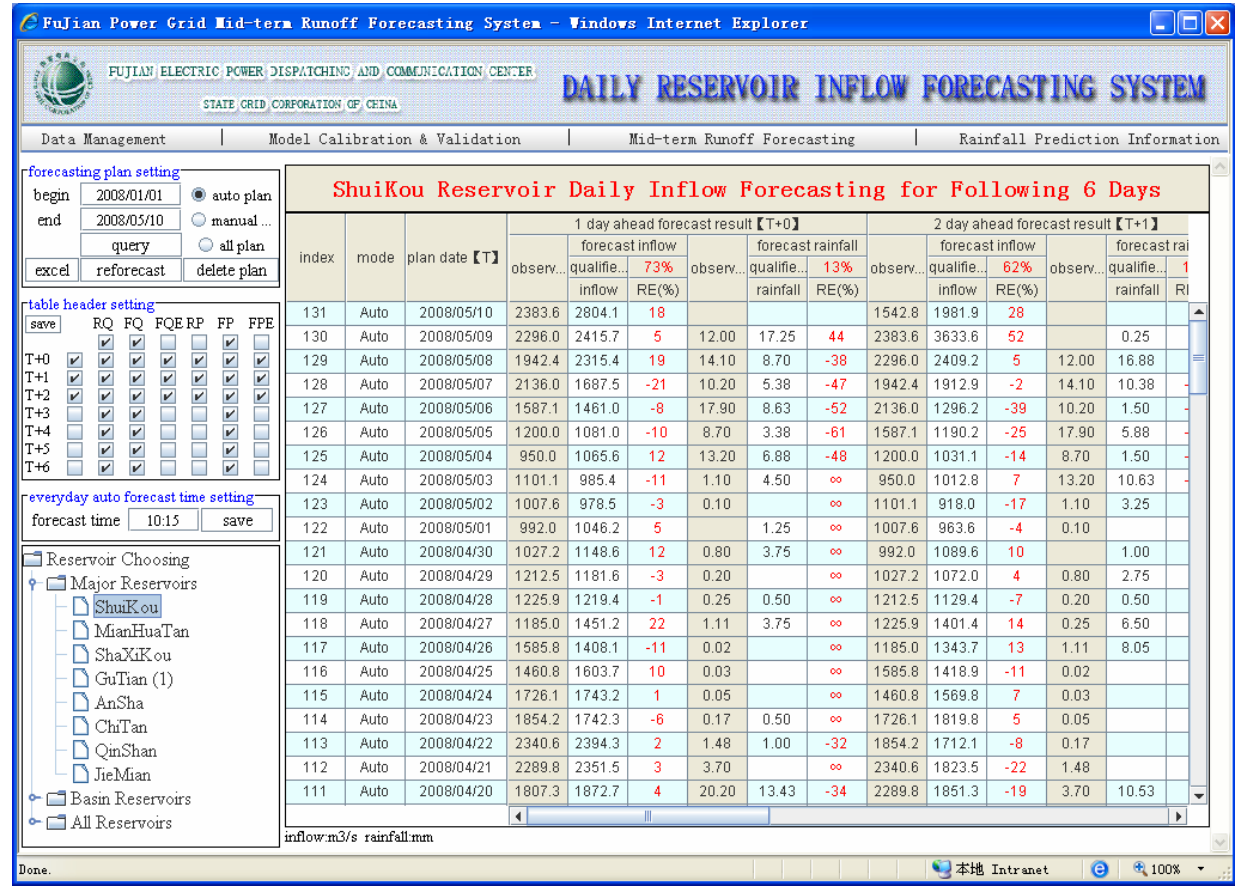

Fig. 7. The auto forecasting module. 


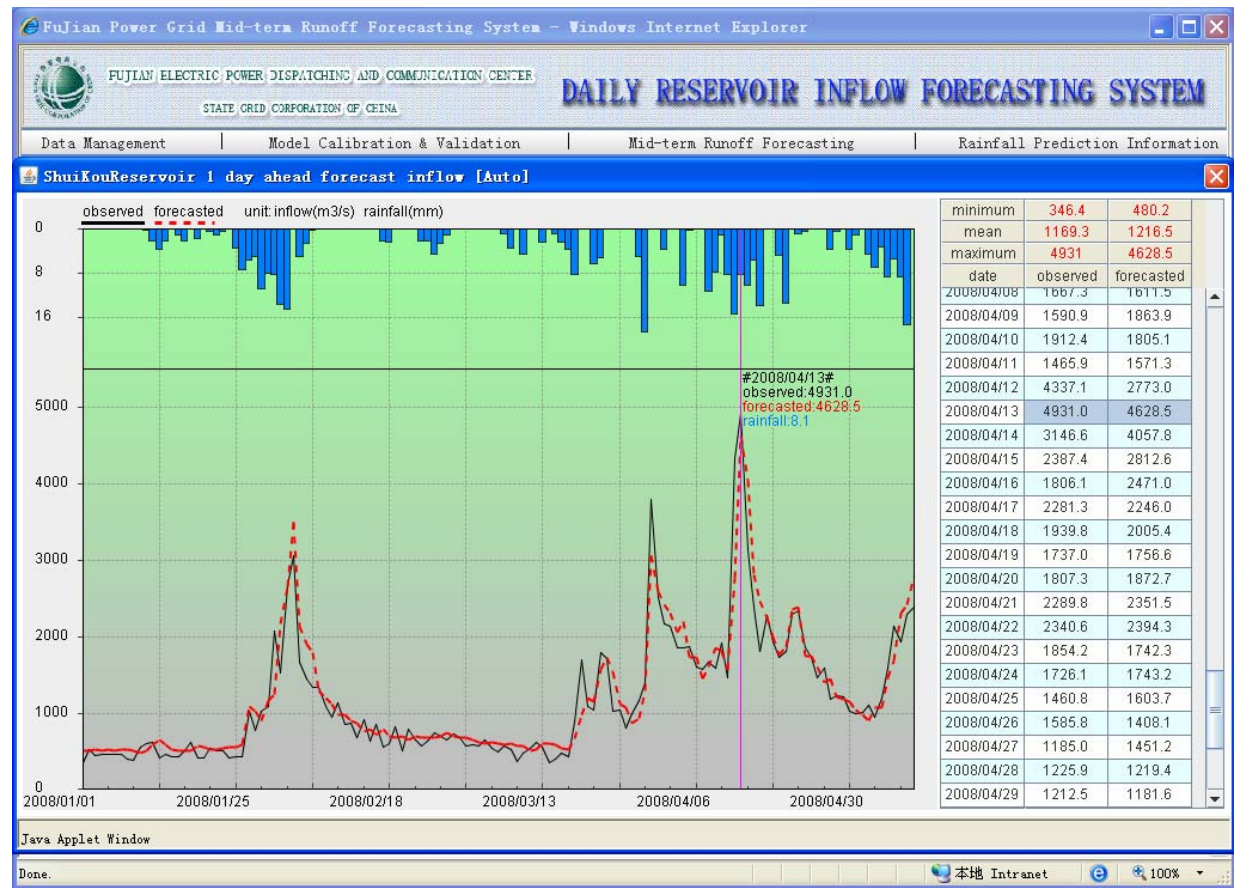

Fig. 8. The forecasted hydrograph and the observed hydrograph (Model $(t+0)$ ).

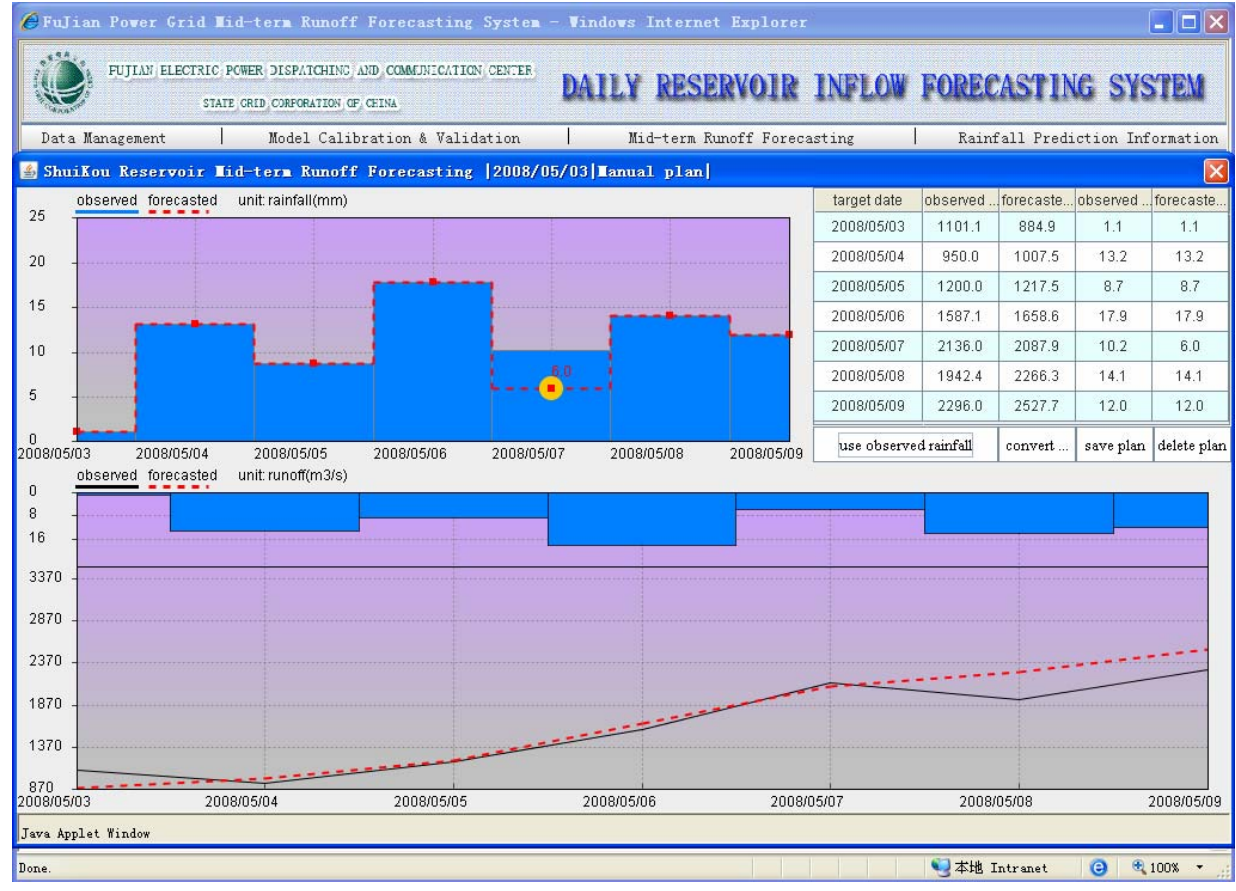

Fig. 9. The simulation forecasting module. 